\title{
Multi Criteria Decision Making In The Selection Of Renewable Energy Power Plants In Indonesia
}

\author{
Zainul M.Pulungan, Bandung Institute of Technology \\ Indonesia \\ zainul.pulungan@sbm-itb.ac.id
}

\author{
Yos Sunitiyoso, Bandung Institute of Techology \\ Indonesia \\ yos.sunitiyoso@sbm-itb.ac.id
}

\begin{abstract}
The long-term strategy of Indonesia's energy resources mix policy for renewable energy supply is targeted to achieve $23 \%$ in 2025 . This is due to the increase of population growth and the growing demands of electricity consumption which is estimated to be around $2,500 \mathrm{kwh} /$ capita in 2025 . Unfortunately, the renewable energy used in 2016 was only $10 \%$ of the total energy production. For this reason, Indonesia plans to convert from non-renewable to renewable energy. This is also in line with Indonesia's commitment to reduce green-house gas emission around $29 \%$ in 2030 as agreed in Paris Agreement (COP 21). Indonesia has several resources of renewable energy. This study aims to determine and to select the appropriate renewable energy power plant for Indonesia's condition and developed criteria of: 1) Economic; 2) Technical; 3) Environmental; and 4) Social. The Methodology used is Multi Criteria Decision Making (MCDM) consisting of Analytical Hierarchy Process (AHP) as the main methodology, and supported by others: MACC, Pairwise Comparison, and SMART. The result shows that the rank of choices is: 1) Hydro; 2) Biomass; 3) Geothermal; 4) Micro-hydro; 5) Solar PV; and 6) Wind. Therefore, this study can be useful for the government to formulate long term energy strategy effectively and efficiency.
\end{abstract}

Keywords-Renewable Energy, Power Plant, Multicriteria Decision Making

\section{INTRODUCTION}

The Energy Law No.30/2007 stated that National Energy Council formulated and plan National Energy Policy (NEP). One of the issues covered in the policy is to address the energy development priority. Moreover, Government Regulation No. 79/2014 regarding the National Energy Policy becomes the operational guidance for management energy policy until 2050. National Energy Policy is formulated as guidance for the management of energy to establish energy independence and security to support national development. Energy independence and security can be achieved through several steps. The initial step is to develop new paradigm: energy resources is no longer a national commodity but it serves as the national development capital. National Energy Policy, as a part of the new paradigm, should establish target supply and utilize primary energy in 2025 and 2050. One of the targets is to develop a power plant with the supply capacity of $115 \mathrm{GW}$ in 2025 and $430 \mathrm{GW}$ in 2050 , and to reach electricity utilization per capita $2500 \mathrm{kwh}$ and $7000 \mathrm{kwh}$. This will ensure energy resources supply as the capital development.

National Energy Policy also establishes the role of renewable energy of, at least, $23 \%$ from total energy consumption in 2025 and $31 \%$ in 2050 . The utilization of renewable energy is expected to reduce the carbon gas emission. The amount of greenhouse gas emission can be obtained through multiplying electricity consumption $(\mathrm{kWh})$ with greenhouse gas emission factor determined earlier. However, the initial investment cost of renewable energy is quite expensive and still under Fossil-fuel Power Plant. Furthermore, Conference of party (COP) 21 about climate change in Paris has agreed that countries in the worldwide should commit to keep threshold temperature rise below 2 degrees Celsius and to limit warming to 1.5 degree Celsius. Indonesia, on the other hand, commits to reduce the greenhouse gas emission for about 29\% in 2030.

Accordingly, it is interesting to study the best renewable energy power plants for Indonesia from the aspects of economic, technical, social, and environmental through a Multi-Criteria Decision Making (MDCM) research method consisting of Analytical Hierarchy Process (AHP) as the main methodology, Marginal Abatement Cost Curve (MACC) to determine the weights of the selection criteria, pairwise comparison matrices of the AHP, and Simple Multi Attribute Rating Technique (SMART) in the analysis.

Indonesia has huge potential and diversified renewable energy resources. However, the development of energy resources should value the economic, technical, environmental, and social aspects of local wisdom. As a consequence, a comprehensive assessment and review are needed to determine the best renewable energy. This research will scientifically focus on:

- determining the important criteria in decision making for renewable energy power plants based on the condition in Indonesia;

- determining the important sub-criteria in decision making for renewable energy power plants based on the conditions in Indonesia;

- giving recommendations on the best renewable energy power plants based on the determined-criteria;

- giving recommendations on the development of the best renewable energy power plants in Indonesia; 
Today, Indonesia is facing a dilemma - how to balance the development of its economy and the extraction of natural resources and increasing energy demand with rising GHG emissions, worsening air pollution, and the loss of the significant natural capital and ecosystem services provided by its forests and their underlying biodiversity. The awareness of Indonesian people and the government of the importance of sustainable development and environmental protection have increased, particularly in water pollution, floods, droughts, urban air quality, forest degradation, illegal logging and fires.

Although Indonesia has a large and diversified renewable energy resources potential, only few of them have been developed. Indonesia has always prioritized the development of renewable energy sources and has formulated a set of ambitious targets for the various renewable energy resources even in the light of increasing world oil prices, decreasing domestic oil production, increasing energy demand, and social and environmental considerations,

With the excellent resources, the need for new power capacity to meet fast-growing demand, the improved longterm renewable targets and sufficient financial incentives, the new portfolio should support Indonesia's renewable energy resources development. Still, there are significant challenges in relation with the strengthening of the grid, the reduction of non-economic developmental barriers, and addressing the cost and availability of financing. Due to the long lead times in the development of hydropower and geothermal, in particular, this will become a delay in the policy implementation which could undermine the realization of 2025 renewable targets.

\section{Criteria for Renewable Energy Power Plant}

Table 1: Selection Criteria for RE Power Plants

\begin{tabular}{|c|c|c|c|}
\hline $\begin{array}{l}\mathbf{N} \\
\mathbf{0}\end{array}$ & Criteria & Indicator & Method \\
\hline \multirow{4}{*}{1} & \multirow{4}{*}{ Economical } & Investment Cost & Marginal Abatement Cost Curve (MACC) \\
\hline & & $\begin{array}{l}\text { Operation and } \\
\text { Maintenance Cost }\end{array}$ & Marginal Abatement Cost Curve (MACC) \\
\hline & & Fuel Cost & Marginal Abatement Cost Curve (MACC) \\
\hline & & $\begin{array}{l}\text { Economic Life of } \\
\text { Project }\end{array}$ & Marginal Abatement Cost Curve (MACC) \\
\hline \multirow{5}{*}{2} & \multirow{5}{*}{ Technical } & $\begin{array}{l}\text { Energy Production } \\
\text { Capacity }\end{array}$ & Marginal Abatement Cost Curve (MACC) \\
\hline & & Capacity Factor & $\begin{array}{l}\text { Simple Multi Attribute Rating Technique } \\
\text { (SMART) }\end{array}$ \\
\hline & & Reliability & $\begin{array}{l}\text { Simple Multi Attribute Rating Technique } \\
\text { (SMART) }\end{array}$ \\
\hline & & Technology Maturity & $\begin{array}{l}\text { Simple Multi Attribute Rating Technique } \\
\text { (SMART) }\end{array}$ \\
\hline & & Distance Location & $\begin{array}{l}\text { Simple Multi Attribute Rating Technique } \\
\text { (SMART) }\end{array}$ \\
\hline \multirow{3}{*}{3} & \multirow{3}{*}{ Enviromental } & $\mathrm{CO}_{2}$ Emission & Pairwise Comparison \\
\hline & & Impact on Ecosystem & $\begin{array}{l}\text { Simple Multi Attribute Rating Technique } \\
\text { (SMART) }\end{array}$ \\
\hline & & Land Use & $\begin{array}{l}\text { Simple Multi Attribute Rating Technique } \\
\text { (SMART) }\end{array}$ \\
\hline \multirow{3}{*}{4} & \multirow{3}{*}{ Social } & Social Acceptability & Marginal Abatement Cost Curve (MACC) \\
\hline & & Job Creation & $\begin{array}{l}\text { Simple Multi Attribute Rating Technique } \\
\text { (SMART) }\end{array}$ \\
\hline & & Social Benefit & Pairwise Comparison \\
\hline
\end{tabular}

\section{RESEARCH METHODS}

In this study, a multi-criteria model was developed to evaluate a particular renewable resource for electricity production in Indonesia. The criteria used would provide a holistic evaluation of a particular renewable resource to a decision maker. These criteria were in line with the Government Regulation No 79/2014. As a matter of fact, there were also fifteen sub-criteria identified to have a direct influence on ranking renewable sources and the goal of the decision problem and used to enrich this model. The main and sub-criteria were also supported by prior studies in the literature reviewed. The AHP model formulated in this study consisted of four levels. At the top level was the decision goal followed by the main criteria at level two. The sub-criteria were at level three, while the various renewable sources were at the fourth level, called alternatives. The structure of the model is depicted in Figure 1.

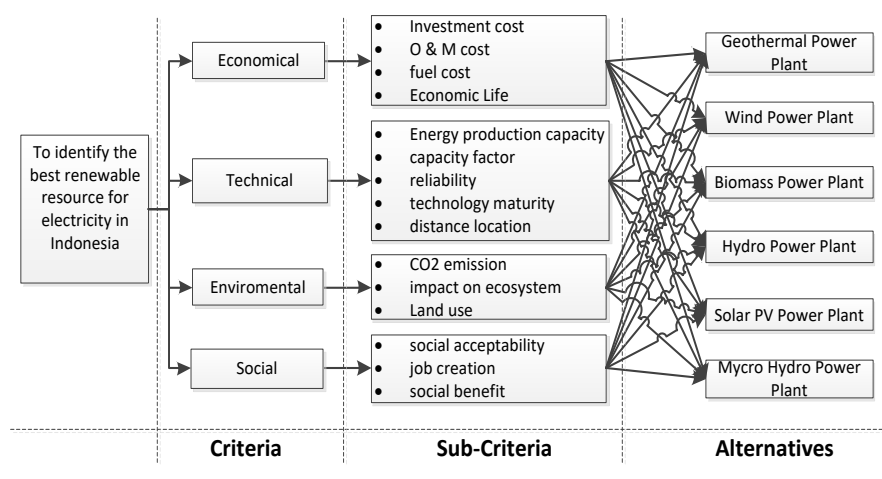

Figure 1: The proposed AHP Model

Research questionnaires were used and distributed to experts in the government, private sectors, environmentalist, socialist, academic, and association. One of the advantages considered in employing AHP method was the consistency test to screen out inconsistent judgments from many experts. It is important that the decision-makers should be consistent in their preference ratings expressed by pairwise comparisons. The first analysis is to check the experts' judgments consistency. It is recommended that the consistency ratio (CR) should be less than 0.10 . When the $\mathrm{CR}$ is greater than 0.10 , it indicates serious inconsistencies and, in this case, the AHP may not provide meaningful results (Saaty, 1980). If the matrix is inconsistent, the evaluations should be repeated until the true consistency ratio is achieved. In this study, it was found that the consistency ratios were varied between $\{0$ and 0.1$\}$. After that, each criterion will be compared one by one based on the scale of importance (see Table 2). Then, the AHP methodology is performed. 
Table 2: AHP Importance Scale

\begin{tabular}{|c|c|c|}
\hline Scale & Description & Explanation \\
\hline 1 & equal important & $\begin{array}{l}\text { Two activities contribute } \\
\text { equally to the objective }\end{array}$ \\
\hline 3 & $\begin{array}{l}\text { Moderate importance of on } \\
\text { over another }\end{array}$ & $\begin{array}{l}\text { Experience and judgement } \\
\text { slightly favor one activity } \\
\text { over another }\end{array}$ \\
\hline 5 & $\begin{array}{lll}\text { Essential or strong } \\
\text { importance }\end{array}$ & $\begin{array}{l}\text { Experience and judgement } \\
\text { strongly favor one activity } \\
\text { over another }\end{array}$ \\
\hline 7 & $\begin{array}{l}\text { Very strong or } \\
\text { demonstrated importance }\end{array}$ & $\begin{array}{l}\text { An activity is strongly } \\
\text { favored and its dominance } \\
\text { is demonstrated in practice }\end{array}$ \\
\hline 9 & Absolute importance & $\begin{array}{l}\text { The evidence favoring one } \\
\text { activity over another is of } \\
\text { the highest possible order } \\
\text { of affirmation }\end{array}$ \\
\hline $2,4,6,8$ & $\begin{array}{lr}\text { Intermediate } & \text { values } \\
\text { between two adjacent } \\
\text { judgements }\end{array}$ & $\begin{array}{l}\text { When compromise is } \\
\text { needed }\end{array}$ \\
\hline $\begin{array}{c}\text { Reciprocal } \\
\text { of above }\end{array}$ & \multicolumn{2}{|c|}{$\begin{array}{l}\text { If activity } \mathrm{A} \text { has one of the above nonzero numbers } \\
\text { assigned to it when compared with activity } \mathrm{B} \text {, then } \mathrm{B} \text { has } \\
\text { the reciprocal value when compared with A }\end{array}$} \\
\hline
\end{tabular}

\section{RESULTS}

Table 3: Relative Weights of Sub-criteria

\begin{tabular}{|c|c|c|c|c|c|c|c|}
\hline Types of Criteria & 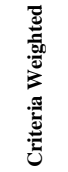 & 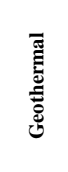 & $\bar{z}$ & 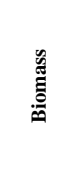 & t) & $\begin{array}{l}\vec{b} \\
\frac{5}{\circ}\end{array}$ & 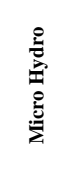 \\
\hline Economical Aspect & 26,70 & $\mathbf{0 , 0 0 4}$ & 0,000 & 0,063 & 0,267 & 0,005 & 0,025 \\
\hline Technical Aspect & 31,10 & 0,250 & 0,124 & 0,200 & 0,228 & 0,175 & 0,191 \\
\hline Capacity factor & 4,85 & 0,036 & 0,016 & 0,033 & 0,017 & 0,013 & 0,015 \\
\hline Reliability & 12,32 & 0,111 & 0,029 & 0,066 & 0,094 & 0,057 & 0,070 \\
\hline Technology Maturity & 8,74 & 0,079 & 0,052 & 0,061 & 0,082 & 0,055 & 0,070 \\
\hline Distance Location & 5,19 & 0,025 & 0,027 & 0,040 & 0,035 & 0,049 & 0,037 \\
\hline Environmental Aspect & 21,90 & 0,087 & 0,085 & $\mathbf{0 , 0 8 0}$ & 0,105 & 0,108 & $\mathbf{0 , 0 8 6}$ \\
\hline Co2 Emission & 4,99 & 0,019 & 0,000 & 0,013 & 0,050 & 0,015 & 0,005 \\
\hline Impact on Ecosystem & 8,87 & 0,041 & 0,053 & 0,044 & 0,035 & 0,071 & 0,056 \\
\hline Land Use & 8,04 & 0,027 & 0,031 & 0,023 & 0,019 & 0,022 & 0,025 \\
\hline Social Aspect & 20,30 & 0,040 & $\mathbf{0 , 0 2 6}$ & $\mathbf{0 , 0 4 2}$ & 0,045 & 0,058 & 0,061 \\
\hline Social Acceptability & 12,38 & 0,013 & 0,011 & 0,018 & 0,016 & 0,032 & 0,034 \\
\hline Job Creation & 2,44 & 0,017 & 0,011 & 0,017 & 0,018 & 0,015 & 0,017 \\
\hline Social Benefit & 5,48 & 0,010 & 0,004 & 0,008 & 0,011 & 0,011 & 0,010 \\
\hline
\end{tabular}

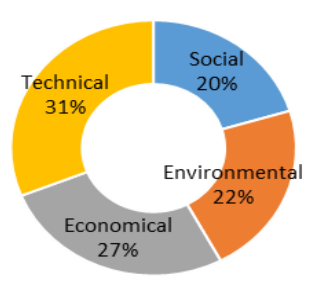

Figure 2 Relative Weights of Criteria with Respect to Goal

Results showed that the technical and economic aspects were indicated as the most important criteria identified by the experts with relative scores of 31,1 and 26,7 respectively (as shown in Figure 2). The environmental aspects appeared to be the third most important factor in the decision making with relative score of 21,9 . The least important factor was the social aspects with relative score of 20,3. The overall inconsistency ratio in the experts' judgments was 0,03 .

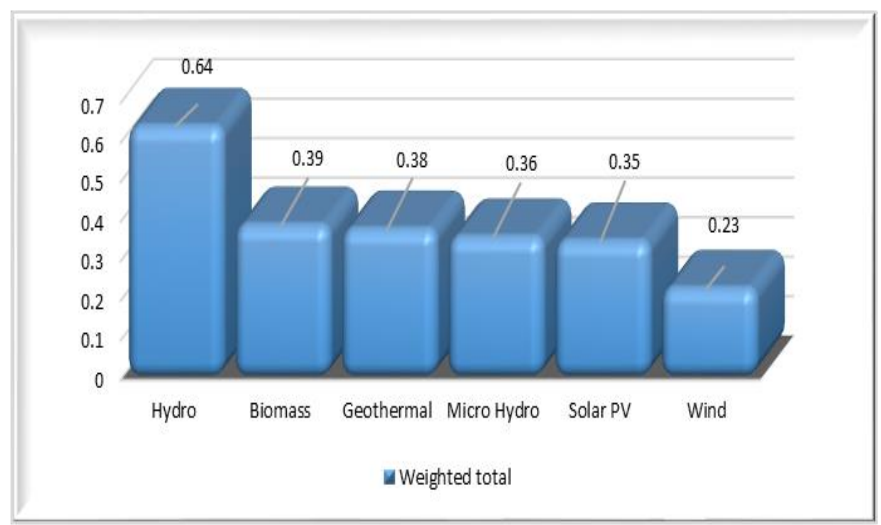

Figure 3 The Rank of Renewable Energy Power Plants

Figure 3 presented the Rank of Renewable Energy Power Plants. Below are the advantages and disadvantages of each power plant based on the analysis done. The description will be in accordance with the overall score and ranking of each power plant. It was found that some plants could be more favorable than others under certain criteria since there is no ideal type of power plant. Hydro-based power plant is at the top rank of other plants with overall score of 0,64 mainly because of the three dominant criteria. The most important criteria taken into account are the renewable energy type potential of $16380 \mathrm{MW}$, the lowest capital cost and the economic life of project is quite long (30 years) comparing to others. Hydro-based power plant has the highest reduction $\mathrm{CO} 2$ emission because the energy production capacity is quite large so that it can mitigate $\mathrm{CO} 2$ emission compared to Diesel Power Plant. From the criteria of technological maturity, social benefit, and job creation, this power plant has the highest score when compared to others. However, the plant got the lowest score for the impact caused on ecosystem and land use. In addition, it is providing financial and technical solution that is mitigating $\mathrm{CO} 2$ emission with high job creation. The second rank is Biomass-based power plant because the fuel cost, and operation and maintenance cost are quite cheap, as well as the capacity factor which is at the second rank with capacity rating of $68,7 \%$ after Geothermal. However, it uses the largest land (5000 km2/1000 MW) affecting the local community based on reference to the literature reviewed. On the other hand, based on experts' judgment, it is at the third rank for the land use with weight score of 0,023 . Furthermore, it has the second highest rank for the impact on ecosystem $(0,44)$ because the great areas required for cultivation is necessary to produce the biomass fuel. The Biomass-based power plant's overall performance score is 0,39. Moreover, Geothermal-based power plant has the highest weight in the reliability sub-criteria $(0,111)$ and capacity rating of $74,3 \%$ for the capacity factor, as well as the lowest cost for operation and maintenance. The land use needed is the smallest (18 km2/1000 MW) based on the literature reviewed. Yet, based on the experts' judgment in Indonesia, it is at the second rank with weight of 0,027 after wind-based power plant. It has the highest fuel cost and the 
lowest weight for distance location $(0,025)$ in comparison to others. As a result, it is ranked at the third favourable energy power plant with the overall score of 0,38 that would provide a sustainable solution in minimizing the land use with high energy production and excellent performance. Micro-hydro based Power Plant is at the fourth position because of the highest weight from the perspective of social acceptability sub-criteria $(0,034)$ and no cost spent for the fuel. However, it has the second lowest rank for capacity factor sub-criteria with the rating of $30 \%$ after the Solar PV power plant. The overall score is 0,36 . The Solar PV power plant is at the fifth position with weight score of 0,35 mainly because the capital cost, operation and maintenance cost are the highest comparing to others, not to mention the lowest performance for the capacity factor with rating $25,8 \%$. It also has the highest weight score for the impact on ecosystem $(0,071)$ and distance location $(0,049)$. Even so, this power plant can be installed at the entire regions in Indonesia from the geographical aspect. Wind power plant is at the last position, mainly because it does not have strong performance (the lowest weight) either in the sub-criteria of reliability, technology maturity, or availability, as well as in the $\mathrm{CO} 2$ emission reduction. Furthermore, it also has the lowest weights in social aspects' sub-criteria, i.e., social acceptability $(0,011)$, social benefit $(0,004)$, and job creation $(0,011)$. However, it has no fuel cost and gives the highest weighted for land use $(0,031)$ because can be used for other activities. The overall score of wind power plant is 0,23 .

\section{DISCUSSION}

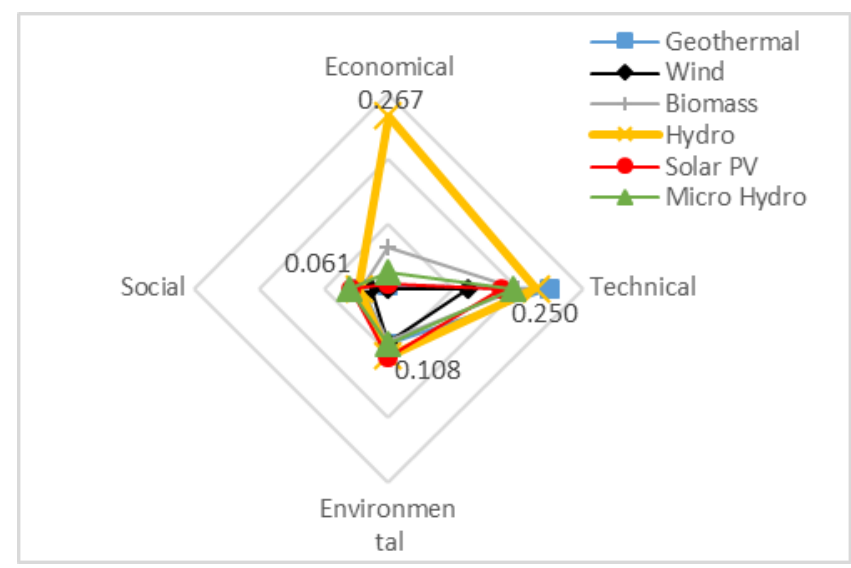

Figure 4 Performance of Renewable Energy Power Plants with Respect to Criteria

Further analysis reveals that none of the renewable energy sources performs well in equal at the four criteria determined. This is clear evidence presented in Figure 4. Hydro-based power plant scores more on the economic criteria $(0,267)$, while Geothermal seems to be a more technically favorable option $(0,25)$. Solar PV power plant performs the best from the perspective of environmental criteria $(0,108)$ and Micro hydro-based power is inclined towards the social criteria $(0,061)$.

\section{CONCLUSIONS}

Indonesia has planned to diversify its energy mix from renewable energy by $23 \%$ in 2025 . To develop a sustainable electricity generation system, a country in this case Indonesia has to incorporate renewable resources in electricity generation. In this study, an overview of various renewable sources has been provided, along with the challenges in their development. It was found that there are several potential resources are available but each of them has its own limitations. There are six types of renewable energy resources which were evaluated for the electricity generation.

The survey instrument was distributed to the experts of the stakeholders. Every expert gave his/ her personal judgment, opinion and priority for the determined criteria and sub criteria, and the alternatives. The experts have quantified that the technical and economic aspects are the most important criteria for selecting and ranking each of the resources with relative scores of 31,1 and 26,7 respectively. The environmental aspect appeared to be the third most important criteria in the decision making with relative score of 21,9. The social aspects was found the least important criteria with the relative score of 20,3. However, the most important sub-criteria was the social acceptability taken into account in the social aspect. The model has showed that each resource is inclined towards a particular criterion: Hydro-based power plant is inclined more towards economical aspect, whereas Geothermal-based power plant is inclined towards the technical aspect. On the other hand, the solar PV power plant is inclined towards the environmental aspect, while the Micro-hydro based power plant is towards the social aspect. Decision makers should take into account all different perspectives for the best solution in consideration of the local culture, social, and policy. The case study showed that Hydro-based Power Plant is the best effective renewable energy source. The utilization of Hydro-based energy on large scale can increase electricity production in the country. It will not only enhance energy security for the country, but also create job opportunities in the villages, and reduce $\mathrm{CO}_{2}$ emission at the same time. It was also indicated from the result that Biomass and Geothermal-based Power Plants could be other preferred alternatives. The utilization of Biomass energy on large scale can increase electrification ratio in the country. Geothermal-based Power Plant can also play an important role in overcoming the energy shortages in the country. It can be used to distribute energy generation closed to the load being served. Micro-hydro based power plant is at the fourth rank due to the worst of resources, while Solar PV is fifth due to their high capital cost. The last alternative is wind power plant because of the least favorable in terms of the resources, technology maturity, and reliability. It is pertinent to bear in mind that no single alternative is ideal for every country. A combination of multiple favorable technologies offers diversity, system redundancy, energy 
independence, and long-term sustainable development. The utilization of these resources can significantly help the country to overcome the electricity shortage, improve living standards of the society, contribute to economic growth of the country, improve rural economy, reduce energy import bill, and ensure environment sustainability. It is also recommended to use the AHP methodology-based decision model for the formulation of the next national and regional renewable energy policy/ roadmaps for the country.

The research can give several recommendations for the government in the policy-making and as considerations in terms of increasing the renewable energy mix in 2025 and electrification ratio, as well as reducing greenhouse gas emission based on analytical hierarchy process (AHP) methodology. The recommendations are:

a. Government should increase the development of renewable energy power plants because it is quite feasible economically and could reduce the greenhouse gas emission. Also, government must make renewable energy business more attractive by giving subsidies and incentive for the renewable energy development infrastructure such as: tax, security energy funding from fossil fuel. Furthermore, the Government should encourage the role of state-owned enterprise in the field of energy, banking, and financial for investment

b. Government must prioritize the implementation of technical aspect as the basis to develop renewable energy power plant and consider indigenous sources in each region as Indonesia is a developing country with limited financial technology resources that needs to minimize the technical risk, supply chain system, and feedstock availability (biomass). Moreover, the selection of technology must consider geographical aspect and easily understood by the local community utilizing the technology. The geographical aspect influences the grid system which is divided into 3 scenarios: isolated area uses off grid, widespread integrated area uses mini-grid, and affordable area uses on-grid;

c. Goverment must develop and increase the domestic industry to support the development of renewable energy plant. It is not only the supply of main components but also the supporting component for the renewable energy projects to increase Indonesia technological maturity;

d. Government must give dissemination enhancement about renewable energy utilization, benefit, environmental preparation to reduce society resistance and local wisdom consideration through intensive approach (society participation in the project). It is expected to increase social acceptability due to one of the key of sustainable development in renewable energy sector. The highest social acceptability in this research is Micro hydro-based power plant;

e. Government should empower the local society by preparing local human resources to operate the technology themselves (training operation and maintenance), prioritizing local employee, encouraging the participation of surrounding society or private sector to invest in renewable energy project for potential optimization;

f. Government should provide integrated, accurate, and update data for renewable energy potential through research by involving all stakeholder, for instance, by providing the limitations of each renewable energy power plants in the process of potential identification and basic specification favorable the regional condition. In addition, local government should also provide potential mapping data and planning for renewable energy development in its region for decentralized/ archipelago model;

g. Government should give priority for region with accurate and high potential data, as well as high social acceptability. Moreover, it must accelerate and prioritize the development of hydro-based energy resource that has accurate potential resources due to lowest capital cost and longest economic life of project.

\section{REFERENCES}

[1] Constitution. (2007). National Energy council clause 6. 30.

[2] Government Regulation. (2014). National Energy Policy clause 4. 79.

[3] Saaty, T. (1980). The Analytic Hierarchy Process: Planning, Priority Setting, Resource Allocation. USA: Mcgraw-Hill International Book Company 